\section{The articular disc surface in different functional conditions of the human temporo- mandibular joint}

\begin{abstract}
Marchetti C, Bernasconi G, Reguzzoni M, Farina A: The articular disc surface in different functional conditions of the human temporo-mandibular joint. J Oral Pathol Med 1997; 26: 278-82. (C) Munksgaard, 1997.
\end{abstract}

The peripheral discal tissue and the surface covering layer have been studied in normal and in variously damaged human temporo-mandibular joint discs. In the normal disc the tissue consisted of dense bundles of fibers and rare fibrocytes. The surface of the disc was covered by a regular basophilic and electron-dense layer. These morphological characteristics persisted also in some pathological dises in which fibrous derangements had already occurred in the deep parts. In very deformed and damaged discs associated with serious functional anomalies, the superficial discal tissue consisted of rare fibers dispersed in a loose ground substance and of an increased number of cells. The superficial coating was formed by an irregular dense lamina and aggregates of various materials containing cellular debris, vesicles, filaments and amorphous components. These deposits are probably due to degeneration processes of discal tissue. This investigation suggests that the superficial discal tissue and the covering layer are together involved in maintaining the functional properties of the articular surfaces. Their structural modification in severe functional anomalies leads to failure in the maintenance of nonadherence conditions and to deterioration of the functional defect.

\section{Marchetti ${ }^{1}$, G. Bernasconi ${ }^{2}$, M. Reguzzoni ${ }^{1}$ and A. Farina ${ }^{1}$} 1/Itituto di Istologia ed Embriologia Generale and ${ }^{2} /$ stituto di Discipline Odontostomatologiche, Università di Pavia, Italy

Key words: articular disc; articular surface; functional anomalies; morphology; temporomandibular joint

Carla Marchetti, Istituto di Istologia ed Embriologia Generale, via Forlanini 10, 27100 Pavia, Italy

Accepted for publication March 3, 1997
The articular disc is a st"uctural component of the temporo-mandibular joint (TMJ). The main function of the disc is the absorption of compression loads from the mandible for protection of the thin temporal bone of the mandibular fossa. The articular disc is a fibrous tissue composed of bundles of collagen fibers embedded in a ground substance with a few fibrocyte- or fibroblast-like cells $(1,2)$.

Derangements of the collagenous fiber network, vascularization of the central avascular part of the disc and modifications in the cellular component are the main structural changes observed in articular discs following different temporo-mandibular joint dysfunction syndromes (3-11).

In previous studies attention was fo- cused on the structural characteristics of the surfaces of the articular discs (12, 13). These emphasized the importance of the articular fibrous tissue in maintaining an intact articular surface and in absorbing frictional effects during articular movements. Moreover, the important role of the superficial proteoglycan lamina in regulating the exchange of molecules between the disc surface and the synovial fluid has been recently underlined (14). These movements of molecules are necessary for load-bearing properties and lubrication of the articular surfaces.

The aim of this study was to investigate the light microscopical and ultrastructural characteristics of the surface of the articular dise in order to correlate the morphological changes to the func- tional condition of the joint and to suggest possible clinical implications.

\section{Material and methods}

Observations were performed on 10 dises removed from patients suffering from TMJ dysfunctions and on one healthy disc obtained at autopsy from a young subject without TMJ diseases in his clinical history. The 10 discs were selected among a larger number of cases in order to examine discs that presented very variable macroscopic features due to different alterations of TMJ function.

After dissection, the central part of each disc (for detailed description see 8-11) was excised, reduced to small pieces and immediately fixed with a 
Fig, 1. Electron micrograph of the superficial region in the healthy control disc. Parallel. dense bundles of collagen fibers and interposed fibrocytes are present. The disc surface is covered by a subtle electron-dense surface lamina (arrows). ( $\times 4000)$

Fig. 2. Electron micrograph of a slightly damaged disc. The superficial region occasionally develops protuberances that are covered by the electron-dense surface lamina (left arrow). ( $\times 4000)$

Fig. 3. Light micrograph of a damaged disc. The superficial discal tissue is composed of a loose connective tissue matrix containing round or oval cells (arrows). Prominent aggregates of basophilic material are present over the superficial surface layer. $(\times 500)$
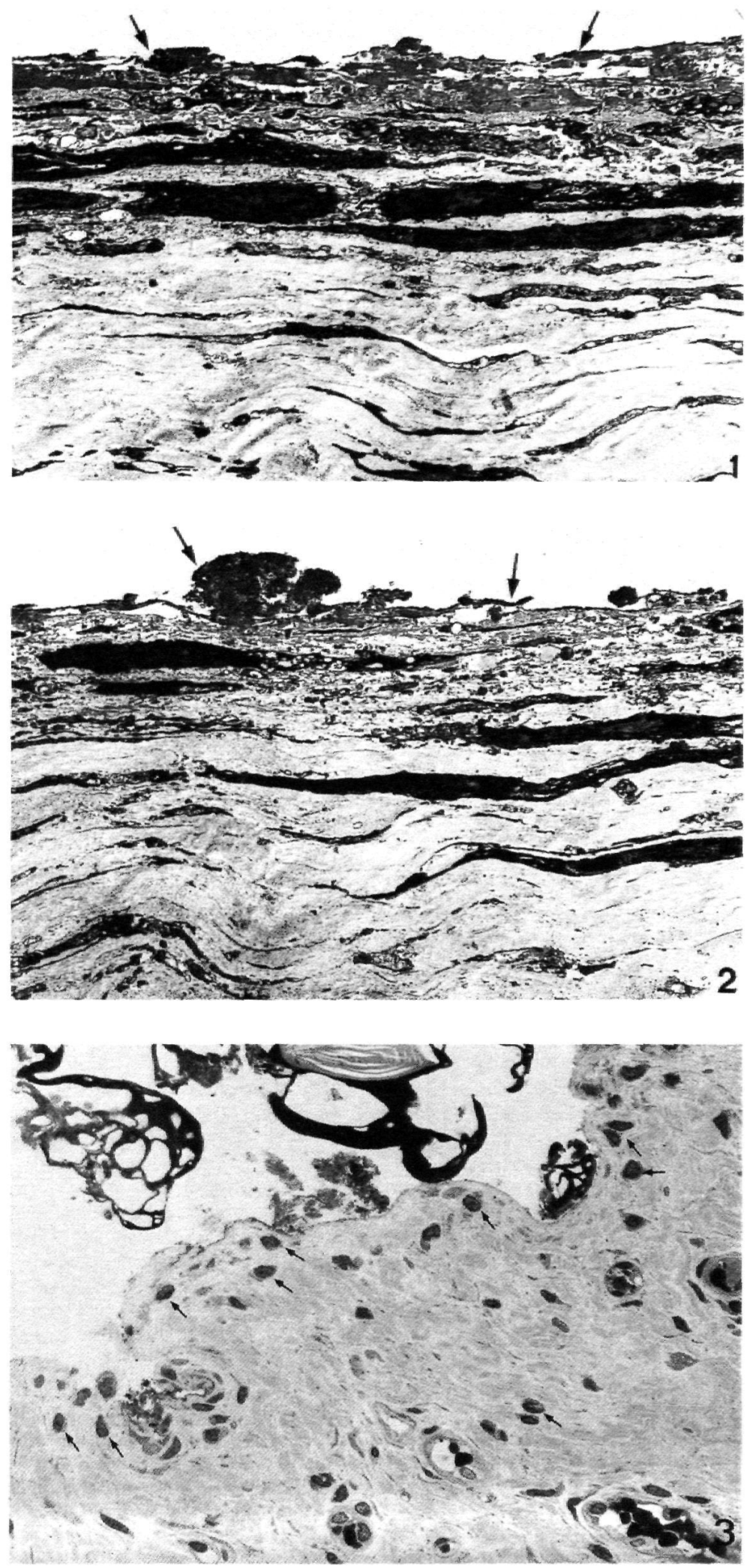
fixative solution of glutaraldehyde $(2.5 \%)$ and paraformaldehyde $(2 \%)$ in $0.1 \mathrm{M}$ sodium cacodylate buffer $(\mathrm{pH}$ 7.4) for $5 \mathrm{~h}$ at $4^{\circ} \mathrm{C}$. The specimens were post-fixed in $0.1 \mathrm{M} \mathrm{OsO} 4$ in $0.2 \mathrm{M}$ collidine buffer $\left(\mathrm{pH} \mathrm{7.4)}\right.$ for $2 \mathrm{~h}$ at $4^{\circ} \mathrm{C}$, dehydrated and embedded in epoxy resin. Semithin sections $(0.5 \mu \mathrm{m})$ for light microscopy were stained with toluidine blue and ultrathin sections $(80$ nm) for transmission electron micro- scopy were contrasted with uranyl acetate and lead citrate.

\section{Results}

In the healthy control disc (Fig. 1) and in those pathological samples with comparatively normal macroscopic features (Fig. 2) the superficial tissue consisted of dense bundles of collagen fibers packed in a scanty ground sub- stance and running in a parallel arrangement to the surface. They were intermingled with rare elongated fibrocytes. The surfaces of these dises were covered by a regular layer $(0.1-1 \mu \mathrm{m}$ thick) of amorphous material. This superficial layer was highly basophilic after toluidine blue staining for light microscopy and at the ultrastructural level it appeared as a very electron-dense material. It showed a lamellar or granular
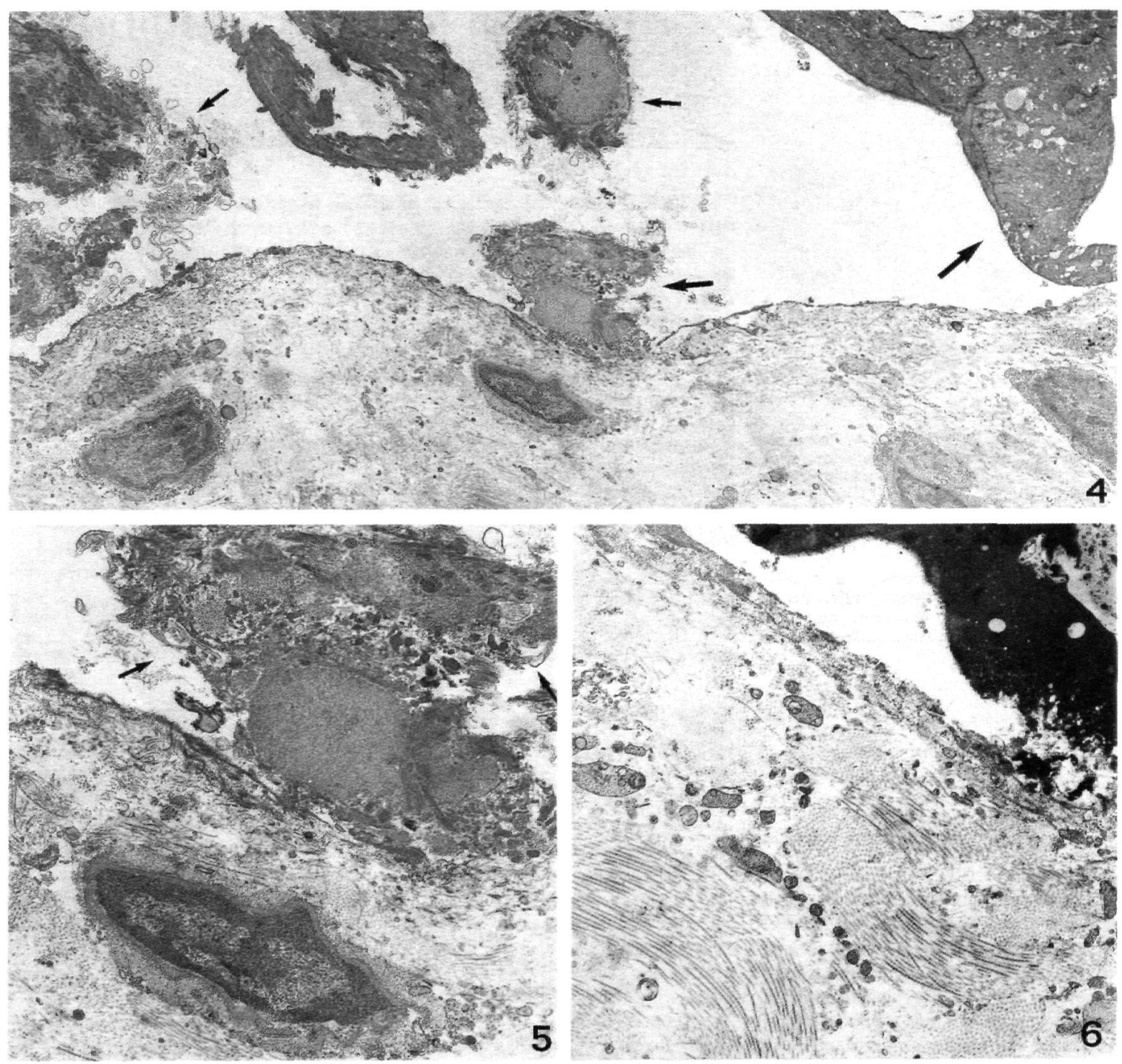

Fig. 4. Electron micrograph of a damaged disc. The abundant connective tissue matrix of the superficial discal tissue contains scanty fibers and some cells. At the surface of the disc, large irregular aggregates of heterogeneous material (arrows) are visible. Note the detachment of some aggregates from the discal surface. $(\times 3150)$

Fig. 5. Higher magnification of part of Fig. 4. A fibroblast-like cell in the superficial discal tissue. One aggregate of dense, amorphous material with cellular debris, vesicles and membranes (arrow) is evident at the surface of the disc. $(\times 8100)$

Fig. 6. Electron micrograph of the loose connective tissue of a damaged disc, with cellular debris, scanty collagenous fibrils and electron-dense amorphous material covering the discal surface. $(\times 8100)$ 


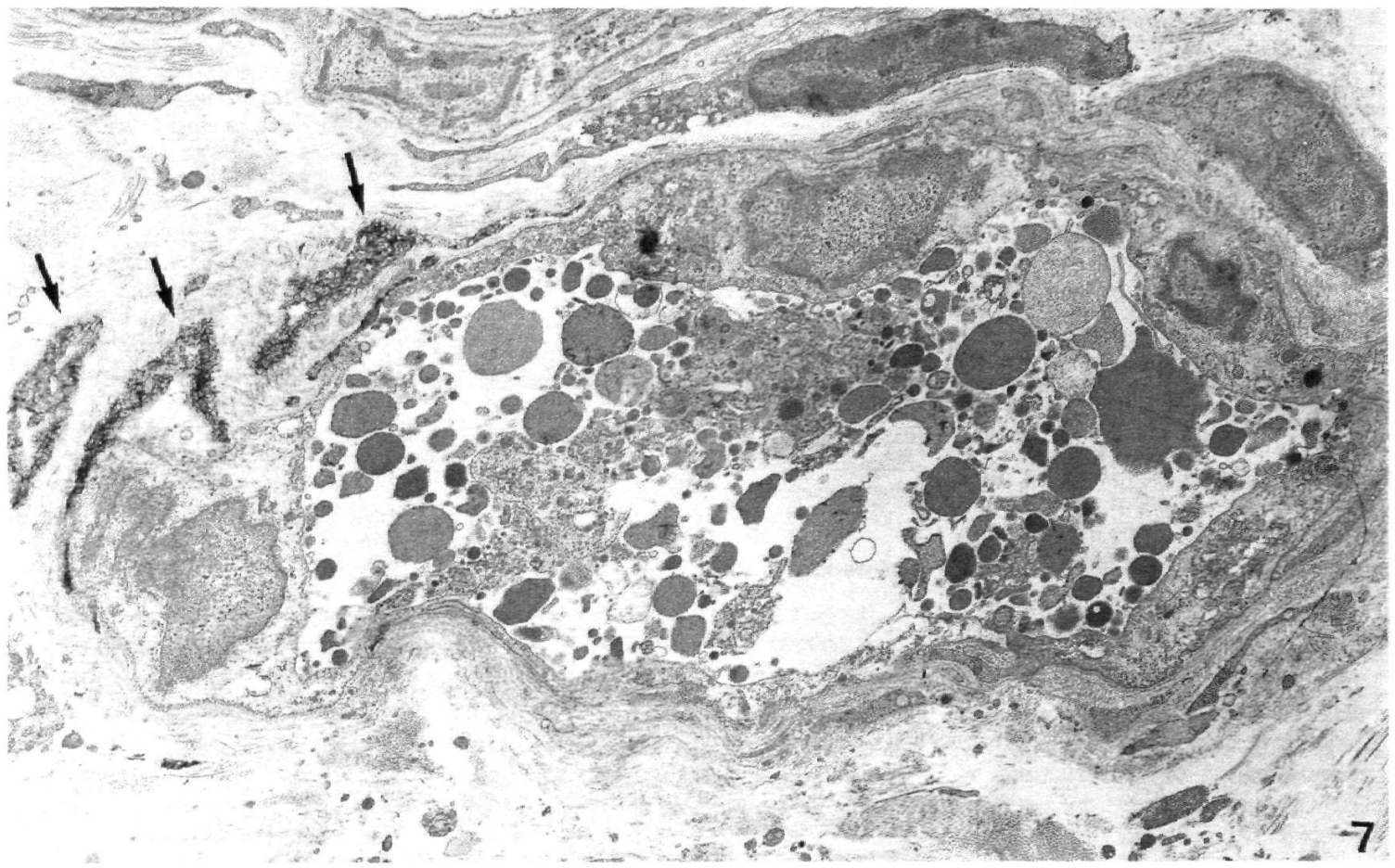

Fig. 7. Electron micrograph of a blood vessel in the inner part of a severely damaged disc. The vessel lumen is occluded by thrombi. Beyond the vessel, foci of mineral aggregates can be detected (arrows). $(\times 5300)$

pattern or was devoid of any apparent structure (Figs. 1, 2). In deeper regions some of the pathological dises presented a less compact fibrous structure, with bundles of irregularly arranged collagen fibers.

In the discs presenting a remarkable degree of modification in their macroscopic shape, with irregular or undulated surfaces, the bundles of collagen fibers were irregularly and loosely arranged and were frequently interwoven in the superficial regions as in the deeper parts. Numerous cells with different shape were present and irregularly distributed among the superficial fibers. Fibers and cells were incorporated into a loose ground substance that was more abundant in pathological discs than in the control disc (Figs. 3, 4). The discal surfaces were irregularly coated by a basophilic layer. In some areas this appeared as a regular lining $(1-3 \mu \mathrm{m}$ thick); in other parts it was gathered in dense and irregular aggregates (Figs. $3-$ 4) and in yet other portions it was completely lacking. On ultrastructural examination some superficial cells presented cytoplasm with a prominent rough endoplasmic reticulum, while other cells (Fig. 5) showed cytoplasm containing residues of cisternae and vacuoles. Cellular debris, vesicles, granules and isolated collagen fibrils were frequently present in the most superficial regions of the fibrous tissue of the pathological discs (Figs. 5-6). Vesicles, granules, filaments, fragments of membranes and probably cellular debris were also present in the amorphous electron-dense material of the superficial coating. In some areas the surface layer was in close connection with the discal tissue, while in other parts it seemed detached from it (Figs. 4-6).

In four severely damaged discs the inner part was vascularized and in two discs the blood vessels showed thickened walls while their lumina were frequently occluded by thrombi. Foci of mineral precipitates were occasionally present (Fig. 7).

\section{Discussion}

Our observations demonstrate that the superficial tissue of the articular disc can undergo significative structural modifications under pathological conditions similar to those described for the inner parts of the disc $(8,10,11)$. Nevertheless, these modifications ap- pear in dises with particularly altered macroscopical features clinically corresponding to severe TMJ dysfunction syndrome. In slightly damaged discs, which had not been subjected to serious functional anomalies, the superficial discal layer maintained structural normality if compared to the already disorganized deep fibrous tissue.

In pathological discs an increase in the number of cells with abundant cytoplasm demonstrates the persisting capacity of the discal tissue to produce new matrix for reparative reconstruction. The appearance of degenerating cells and cellular debris represents morphological indications of a degenerative process in the discal tissue.

The basophilic staining and the ultrastructural features confirm the possible proteoglycan nature of the surface lamina in the healthy disc or in the slightly damaged discs.

A synovial origin has been proposed for the articular surface lamina in healthy discs under normal conditions $(14,15)$. The increase in thickness and the irregular distribution and composition of the surface covering layer in some damaged discs suggest that this layer is involved in the pathogenesis of 


\section{MARCHETTI et al.}

the discal modifications. In particular, vesicles, filaments and granules present in the large aggregates at the surface of severely damaged discs resemble the cellular debris of the adjoining superficial discal tissue. They may be the result of a degenerative process impairing the metabolism of all discal tissues, as demonstrated by the presence of foci of mineral aggregates and other pathological phenomena. Such a degenerative process could result in the accumulation of cellular remnants and their detachment into the joint spaces.

Our observations suggest that the disc can also be involved in the accumulation of material at the articular surface of the condyle or the temporal fossa. This event may be responsible for a successive impairment in the lubrication of the joint and the failure of articular movements.

In summary, we draw two main conclusions concerning the morphofunctional correlations in the TMJ: 1) The preservation of the structural integrity is guaranteed by the articular movements and by the correct displacement of the loading forces applied to the articular surfaces. 2) Structural modifications initially occur in the deep regions of the disc because these parts mainly experience the variations in intensity of mechanical stimuli.

This study demonstrates that the superficial discal tissue and the covering layer play a fundamental role in maintenance of the nonadherence condition of the articular surfaces. The simultaneous development of structural modifications in both components of the disc demonstrates their close morphological and functional correlation. Moreover, the discal articular surface seems to have the capaci- ty to make functional compensations when tissue alterations have already occurred in the deep regions. Structural alterations in the disc surface occurring in serious and chronic functional TMJ diseases may be responsible for the successive deformation or adherence and immobilization of the disc in some cases of joint locking.

Acknowledgements - This research was supported by grants from the Italian Ministry of University and Scientific and Technological Research (MURST). The authors thank E.

Padula and U. Baciliero from "S. Bortolo Hospital "of Vicenza for their valuable collaboration.

\section{References}

1. Bhussry BR, Suarez Fr, Sharawy M. Temporomandibular joint In: BHASKAR SN ed. Orban's oral histology and embryology, 2nd edn. St. Louis: MosbyYear Book Inc., 1991: 406-17.

2. BERKOVITZ BK, Holland GR, Moxam BJ. A colour atlas and textbook of oral anatomy, histology and embryology. London: Wolfe Publ. Ltd, 1992: 217-9.

3. Sharawy M, LaRke V Helmy E. Ultrastructural alterations in monkey TMJ following disc perforation. J Dent Res 1987; 66 (suppl): 119 (abstract).

4. Helmy E, Bays R, Sharawy M. Osteoarthrosis of the temporomandibular joint following experimental disc perforation in Macaca fascicularis. I Oral Maxillofac Surg 1988; 46: 979-90.

5. Helmy es, bays Ra, Sharawy MM Histopathological study of the human TMJ perforated disk with emphasis on synovial membrane response. $J$ Oral Maxillofac Surg 1989; 47: 1048-52.

6. Kurita K. Westesson PL. Sternby NH. et al. Histologic features of the temporomandibular joint disk and posterior disk attachment: comparison of symptomfree person with normally positioned disks and patients with internal derange- ment. Oral Surg Oral Med Oral Pathol 1989; 67: 635-43.

7. Shengyi T,Yinghua X. Biomechanical properties and collagen fiber orientation of TMJ disks in dogs. Part 1. Gross anatomy and collagen fiber orientation of the disks. $I$ Craniomandib Disord Facial Oral Pain 1991; 5: 28-34.

8. Piacentini C, Marchetti C, BernasConi G, Menghini P, Baciliero U, Brusotт1 C. Collagen fiber arrangement in temporo-mandibular joint (TMJ) disks from human subjects with functional diseases. Scanning electron microscopy investigations. Scanning Microsc 1994; 8: 207-13.

9. Piacentini C, Marchetti C, Callegari A, et al. Endoarticular loose bodies and calcifications of the disk of the temporomandibular joint. Morphological features and chemical composition. Scanning Microsc 1995; 9: 789-96.

10. Marchetti C, Reguzzoni M, Farina A, Placentini C, Bernasconi G, BacilIERO U. Myofibroblasts in the fibrous tissue of disks from human temporomandibular joints with functional diseases. Europ J Histochem 1995; 39 (suppl 1): 67 (abstract).

11. Marchetti C, Piacentini C, Farina A, Bernasconi G, Calligaro A. A mictoscopic and immunocytochemical study of structural changes in dysfunctional human temporomandibular joint discs. Arch Oral Biol 1995; 40: 549-57.

12. Pullinger AG, Baldioceda F. BibB CA. Relationship of TMJ articular soft tissue to underlying bone in young adult condyles. J Dent Res 1990; 69: 1512-8.

13. BibB CA, Pullinger AG. The articular synovial lining tissue system in temporomandibular joints of young adults. $J$ Orofacial Pain 1993; 7: 241-6.

14. Shaw RM, Molineux GS. Age-related changes to the surface ultrastructure of the rabbit temporomandibular disc. $J$ Anat 1994; 185: 577-85

15. Balazs EA. Viscoelastic properties of hyaluronic acid and biological lubrication. Univ Michigan Med Center J 1968; 3: $255-9$ 
This document is a scanned copy of a printed document. No warranty is given about the accuracy of the copy. Users should refer to the original published version of the material. 